\title{
Left Ventricular Dysfunction in Asymptomatic Pediatric left ventricular outflow tract obstruction
}

\author{
Heba MH Abozeid
}

Pediatric Department, Zagazig University, Egypt.

\begin{abstract}
:
Background: Tissue Doppler imaging (TDI) has improved the ability to detect subclinical changes in left ventricular (LV) function. The aim of this study was to investigate if asymptomatic patients with left ventricular outflow tract obstruction (LVOTO) had impaired LV systolic and diastolic function. Methods: Twenty-four asymptomatic patients with LVOTO and 26 healthy control subjects were evaluated clinically and by conventional \& tissue Doppler echocardiography. TDI evaluation of longitudinal and radial tissue velocities in systole and diastole was performed. Results: lower conventional pulsed-wave Doppler peak E \& A velocities of trans-mitral filling were observed in patients with LVOTO compared to controls ( $81 \pm 21 \& 77 \pm 31$ VS $66 \pm 14 \& 58 \pm 16 \mathrm{~cm} / \mathrm{sec}$, $\mathrm{p}<0.01$ ). Lower longitudinal tissue velocities were found in patients compared with controls in terms of peak systolic tissue velocity, peak early diastolic tissue velocity $(\mathrm{Em})$, peak late diastolic tissue velocity (Am) \& peak systolic strain (4.15 $\pm 1.1,4.3 \pm 1.6,5.5 \pm 1.5 \mathrm{~cm} / \mathrm{sec} \&-16.5 \pm 2.3 \%$ vs. 4.9 \pm 1 , $5.1 \pm 1.6,6.3 \pm 1.4 \mathrm{~cm} / \mathrm{sec} \&-17.7 \pm 1.9 \%, p<0.05)$. No significant affection of radial tissue velocities was found in LVOTO patients. Conclusion: Subclinical LV systolic and diastolic dysfunction is present in our patients demonstrated only in longitudinal myocardial fibres suggesting a differential effect of LVOTO on the LV musculature or early impairment of the longitudinal myocardial fibres.
\end{abstract}

Keywords: Tissue Doppler imaging, LVOTO, children

\section{Introduction:}

The onset of clinical symptoms and left ventricular systolic dysfunction in patients with LVOTO determine a poor prognosis, the standard echocardiographic evaluation of LV dysfunction, only based on measurements of the LV ejection fraction (EF), may be insufficient for an early assessment of imminent heart failure. In contrary, 2-dimensional speckle tracking (2DS) seems to be superior in detecting subtle changes in myocardial function ${ }^{(1)}$.

Long-axis function, measured by tissue Doppler imaging (TDI), is a sensitive tool for left ventricular (LV) diastolic function assessment $^{(2)}$. Early diastolic velocity (Em) on TDI, in particular, has been widely used in clinical settings because of its easier acquisition, less interference by normal variations in heart rate and loading conditions, and higher accuracy than the conventional spatial peak early mitral inflow velocity ( $E$ ) in assessing diastolic func$\operatorname{tion}^{(3)}$. The aim of this study was to investigate if asymptomatic patients with left ventricular outflow tract obstruction (LVOTO) had impaired LV systolic and diastolic function. 


\section{Patients and Methods:}

This study included 24 asymptomatic patients with LVOTO, aged 22.8 \pm 21.6 months, including 4 patients with bicuspid aortic valves, 12 patients with AS, 5 patients with sub-AS and 3 patients with supra-AS, and with trans-aortic pressure gradient of 42 to $69 \mathrm{mmHg}$.. Three patients were excluded because of technical damage of storage discs with insufficient quality of echocardiographic data. Twenty-six healthy gender- and age-matched controls were included for comparison. Controls underwent similar echocardiographic and clinical examinations as the patients with LVOTO.

All echocardiographic recordings were performed using a $7 \mathrm{~s} \& 12 \mathrm{~s}-\mathrm{MHz}$ transducers (Vivid-7; GE Ultrasound) with simultaneous ECG recording at The Echocardiography Laboratory of Children's Hospital, Zagazig University. The recordings were performed from standard parasternal long- and short-axis and apical 4- chamber views.

LV internal dimensions, septal and posterior wall thicknesses were measured as recommended by the American Society of Echocardiography ${ }^{(4-6)}$. The LV ejection fraction \& Fractional shortening were calculated using the modified Simpson's rule from biplane 4-chamber and long-axis views $^{(7)}$. LV diastolic function was assessed by the peak velocities of the pulsed Doppler transmitral E \& A filling waves ${ }^{(8)}$. Apical color TDI loops (4-chamber views) were used. In patients and controls with suboptimal views, minor changes from the recommended 4-chamber positions were performed to align the segment of interest at the centre of the 2D-sector. Peak systolic and diastolic longitudinal early (Em) and atrial (Am) tissue velocities were measured in the basal and middle segments of the LV septal, lateral, inferior, and anterior walls. Peak tissue velocities from these 8 segments were averaged to get an evaluation of overall LV longitudinal systolic and diastolic function (Figure 1). Strain, which is a measure of tissue deformation, is the relative change in length of a myocardial segment, expressed as a percentage, where shortening (longitudinal axis) refers to a negative value and thickening (radial axis) to a positive value. Strain is calculated as (It - Ito)/lto, where It is the length of the segment at time $t$, and Ito is the initial length.9 Radial tissue velocities and strain from the posterior wall, septum, lateral and anterior walls using loops from parasternal short-axis views, were measured and averaged. 10-12 measurements of all M-mode, 2-dimensional, and pulsed Doppler data were averaged from 1 heart cycle while the tissue velocities and strain were measured from 3 consecutive heart cycles to maximise TDI data acquisition.

\section{Statistical analysis:}

Data were expressed as sample mean \pm SD. For comparison of the data, unpaired Student's $t$ test \& Chi-square test were performed. Values of 0.05 or less was regarded as statistically significant $\& \mathrm{p}$ values of 0.01 or less was considered as highly significant ${ }^{(10,11)}$.

\section{Results:}

Clinical characteristics of patients with LVOTO and the controls are listed in Table 1. Eighteen of the patients had LV hypertrophy as measured by electrocardiography, and 15 showed other pathologic findings, such as decreased $R$ wave progression on anterior chest leads $(n=3)$; right bundle branch block or left bundle branch block $(n=12)$; sinus bradycardia for age $(n=2)$. All ECG results were normal in the controls. 
The LV ejection fractions and fractional shortening were similar in patients and control groups $(65.1 \pm 8.1 \& 42.5 \pm 7.8$ vs. $64.2 \pm 7.5 \& 40.1 \pm 6.7 \%$, respectively, $p$ values >0.05). LV septal and posterior wall thicknesses were significantly increased in the patients with LVOTO compared with the controls (Table 2). Peak systolic longi- tudinal tissue velocity $(4.15 \pm 1.1$ vs. $4.9 \pm 1 \mathrm{~cm} / \mathrm{s}, \mathrm{p}<0.01)$ and strain $(-16.5 \pm 2.3 \%$ vs. $-17.7 \pm 1.9 \%, p<0.05$, (Table 3 ) were significantly lower in the LVOTO group than in the control group. Other differences in TDI indices of LV diastolic relaxation between patients with LVOTO and controls are listed in Table 3.

Table 1: Clinical characteristics of patients with LVOTO and controls

\begin{tabular}{|l|lll|}
\hline Variable & $\begin{array}{l}\text { Patients with AS } \\
(\mathrm{n}=24)\end{array}$ & $\begin{array}{l}\text { Controls } \\
(\mathrm{n}=26)\end{array}$ & $\mathrm{p}$ value \\
\hline Age (months) & $22.8 \pm 21.6$ & $31.2 \pm 24$ & 0.19 \\
Gender: & $15(62.5 \%)$ & $16(61.5 \%)$ & 0.9 \\
- Male & $9(37.5 \%)$ & $10(38.5 \%)$ & \\
- Female & $9.3 \pm 5$ & $12.5 \pm 4.9$ & $0.03^{*}$ \\
Weight $(\mathrm{kg})$ & $0.76 \pm 0.17$ & $0.86 \pm 0.19$ & $0.05^{*}$ \\
Height $(\mathrm{m})$ & $87 \pm 7.9$ & $86.1 \pm 8.1$ & 0.8 \\
Systolic blood pressure $(\mathrm{mmHg})$ & $59.1 \pm 4$ & 0.6 \\
Diastolic blood pressure $(\mathrm{mmHg})$ & $60 \pm 3$ & $105 \pm 14$ & 0.07 \\
Heart rate (beats/min) & $110 \pm 15$ & & \\
*=statistically-significant & &
\end{tabular}

Table 2: Left ventricular M-mode and trans-mitral flow by conventional pulsed Doppler in patients with LVOTO and controls

\begin{tabular}{|l|lll|}
\hline Variable & $\begin{array}{l}\text { Patients with AS } \\
(\mathrm{n}=24)\end{array}$ & $\begin{array}{l}\text { Controls } \\
(\mathrm{n}=26)\end{array}$ & p value \\
\hline M-mode: & & & \\
- End-diastolic diameter $(\mathrm{cm})$ & $3 \pm 0.6$ & $3 \pm 0.5$ & 0.8 \\
- End-systolic diameter $(\mathrm{cm})$ & $1.49 \pm 0.4$ & $1.6 \pm 0.5$ & 0.3 \\
- Septal wall thickness $(\mathrm{cm})$ & $0.5 \pm 0.1$ & $0.34 \pm 0.1$ & 0.000 \\
- Posterior wall thickness (cm) & $0.43 \pm 0.1$ & $0.32 \pm 0.1$ & 0.000 \\
- Ejection fraction (\%) & $65.1 \pm 8.1$ & $64.2 \pm 7.5$ & 0.8 \\
- Fractional shortening (\%) & $42.5 \pm 7.8$ & $40.1 \pm 6.7$ & 0.2 \\
Trans-mitral flow (by pulsed Doppler): & & & \\
- E velocity (cm/s) & $81 \pm 21$ & $66 \pm 14$ & $0.004^{* *}$ \\
- A velocity (cm/s) & $77 \pm 31$ & $58 \pm 16$ & $0.008^{* *}$ \\
- E/A ratio & $1.05 \pm 0.6$ & $1.1 \pm 0.8$ & 0.16 \\
\hline
\end{tabular}

*= statistically-significant; **=highly statistically-significant

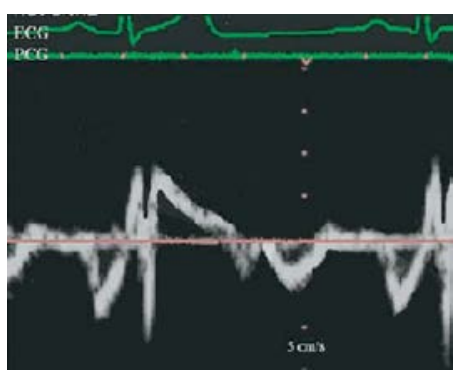

Figure 1: A tissue Doppler image from a patient with LVOTO showing low Em. 
Table 3: TDI-derived longitudinal and radial peak systolic and diastolic velocities and systolic strain in patients and in controls

\begin{tabular}{|l|lll|}
\hline Variable & $\begin{array}{l}\text { Patients } \\
(\mathrm{n}=24)\end{array}$ & $\begin{array}{l}\text { Controls } \\
(\mathrm{n}=26)\end{array}$ & p value \\
\hline Longitudinal velocities: & & & \\
- Peak systolic tissue velocity $(\mathrm{cm} / \mathrm{s})$ & $4.15 \pm 1.1$ & $4.9 \pm 1$ & $0.01^{* *}$ \\
- Peak Em diastolic tissue velocity $(\mathrm{cm} / \mathrm{s})$ & $4.3 \pm 1.6$ & $5.1 \pm 1.6$ & $0.08^{*}$ \\
- Peak Am diastolic tissue velocity (cm/s) & $5.5 \pm 1.5$ & $6.3 \pm 1.4$ & $0.05^{*}$ \\
- Peak systolic tissue strain $(\%)$ & $-16.5 \pm 2.3$ & $-17.7 \pm 1.9$ & $0.05^{*}$ \\
Radial velocities: & & & \\
- Peak systolic tissue velocity (cm/s) & $3.7 \pm 1$ & $3.6 \pm 1.1$ & 0.7 \\
- Peak early diastolic tissue velocity (cm/s) & $5.6 \pm 2$ & $5.7 \pm 2.4$ & 0.8 \\
- Peak systolic tissue strain $(\%)$ & $+39.1 \pm 14.5$ & $+35.8 \pm 13$ & 0.3 \\
\hline
\end{tabular}

*= statistically-significant; **=highly statistically-significant

\section{Discussion}

It has been proposed that abnormal diastolic measurements do not necessarily reflect intrinsic diastolic disease because they are greatly affected by age, systole \& abnormalities of ventricular activation ${ }^{(13)}$. Patients with LVOTO could develop symptoms despite having a normal LV ejection fraction \& fractional shortening, and this has been attributed to diastolic dysfunction associated with increased diastolic stiffness and elevated filling pressures ${ }^{(14)}$.

Our data suggest early and late diastolic dysfunction in LVOTO patients evidenced by reduced peak Em and Am diastolic tissue velocities in patients vs. control. Our patients with LVOTO were found to have subclinical impaired systolic LV function as measured by decreased peak systolic tissue velocities and strain despite having maintained systolic function in terms of conventional FS \& EF. Our findings agree with previous studies that showed reduced early systolic \& early diastolic velocities as measured by $\operatorname{TDI}^{(15,16)}$. In experimental studies, peak systolic longitudinal tissue velocities and strain have demonstrated good correlations with invasive measurements of $\mathrm{LV}+\mathrm{dP} / \mathrm{dt}$ and stroke volume, respectively ${ }^{(17,18)}$. More- over, we believe that our finding of no affection of systolic radial tissue velocities and strain in patients with LVOTO emphasizes that this group of patients have impaired LV systolic function with a differential effect on myocardial fibers.

Similar to the subjects in those studies, our LVOTO group also showed diastolic dysfunction by conventional pulsed wave Doppler trans-mitral E \& A velocities, which supports the view that LV systolic dysfunction develops in parallel with diastolic dysfunction ${ }^{(19,20)}$. Impaired relaxation in LVOTO as a consequence of LV hypertrophy has been demonstrated by others, but the patients in those studies had more severe LVOTO $^{(21)}$. In a study including patients with severe AS, Bruch et al $^{(22)}$ demonstrated a high $E / E$ ' septal ratio and a good correlation with invasive LV filling pressures. The significant increases we observed in LV septal and posterior wall thicknesses in patients with LVOTO have previously been demonstrated by others $^{(23)}$.

\section{References:}

1- Dinh W, Nickl W, Smettan J, Kramer F, Krahn T, Scheffold T, Barroso MC, Brinkmann $\mathrm{H}$, Koehler T, Lankisch M, Füth R. Reduced global longitudinal strain in 
association to increased left ventricular mass in patients with aortic valve stenosis and normal ejection fraction: a hybrid study combining echocardiography and magnetic resonance imaging. Cardiovasc Ultrasound. 2010; 26;8:29.

2. Henein MY, Gibson DG. Long axis function in disease. Heart 1999; 81:229-231.

3. Yamamoto K, Nishimura RA, Chaliki HP, Appleton CP, Holmes DR Jr, Redfield MM. Determination of left ventricular filling pressure by Doppler echocardiography in patients with coronary artery disease: critical role of left ventricular systolic function. J Am Coll Cardiol 1997 ; 30:1819 1826.

4. Sahn DJ, DeMaria A, Kisslo J, Weyman A. Recommendations regarding quanititation in M-mode echocardio-graphy: results of a survey of echocardiographic measurements. Circulation 1978; 58:10721083.

5. Devereux RB, Alonso DR, Lutas $E M$, Gottlieb GJ, Campo E, Sachs I, Reichek N. Echocardiographic assessment of left ventricular hypertrophy: comparison to necropsy findings. Am J Cardiol 1986; 57:450- 458.

6. Frohlich ED, Apstein C, Chobanian AV, Devereux RB, Dustan HP, Dzau V, FauadTarazi F, Horan MJ, Marcus M, Massie B, et al. The heart in hypertension. $N$ Engl J Med 1992;327:998-1008.

7. Schiller NB, Shah PM, Crawford M, DeMaria A, Devereux R, Feigenbaum H, Gutgesell H, Reichek N, Sahn D, Schnittger I. Recommendations for quantitation of the left ventricle by two-dimensional Echocardiography . American Society of Echocardiography Committee on Standards, Subcommittee on Quantitation of TwoDimensional Echocardiograms. J Am Soc Echocardiogr 1989; 2:358 -367.

8. Oh JK, Appleton CP, Hatle LK, Nishimura RA, Seward JB, Tajik AJ.The non-invasive assessment of left ventricular diastolic function with two- dimensional and Doppler echocardiography. J Am Soc Echocardiogr 1997;10:246 -270.

9. Urheim S, Edvardsen $\mathrm{T}$, Torp $\mathrm{H}$, Angelsen B, Smiseth OA Myocardial strain by Dop- pler echocardiography. Validation of a new method to quantify regional myocardial function. Circulation 2000; 102:1158 -1164 .

10. Nagueh SF, Middleton KJ, Kopelen HA, Zoghibi WA, Quinones MA. Doppler tissue imaging: a non-invasive technique for evaluation of left ventricular relaxation and estimation of filling pressures. J Am Coll Cardiol 1997;30:1527-1533.

11. Ommen SR, Nishimura RA, Appleton CP, Miller FA, Oh JK, Redfield MM, Tajik AJ. Clinical utility of Doppler echocardiography and tissue Doppler imaging in the estimation of left ventricular filling pressures: a comparative simultaneous Doppler-catheterization study. Circulation 2000; 102:1788 -1794.

12. Garcia MJ, Ares MA, Asher C, Rodriguez L, Vandervoort P, Thomas JD. An index of early left ventricular filling that combined with pulsed Doppler peak E velocity may estimate capillary wedge pressure. J Am Coll Cardiol 1997; 29:448-454.

13. Gibson DG, Francis DP. Clinical assessment of left ventricular diastolic function. Heart 2003;89:231-238.

14. Hess OM, Villari B, Krayenbuehl HP. Diastolic dysfunction in aortic stenosis. Circulation 1993;87(suppl IV):IV-73-IV-76.

15. Bruch C, Stypmann J, Grude M, Graduas R, Breithardt G, Wichter T. Tissue Doppler imaging in patients with moderate to severe aortic valve stenosis: clinical usefulness and diagnostic accuracy. Am Heart J 2004;148:696-702.

16. Kiraly P, Kapusta L, Thijssen JM, Daniels $O$. Left ventricular myocardial function in congenital valvular aortic stenosis assessed by ultrasound tissue-velocity and strain-rate techniques. Ultrasound Med Biol 2003; 29:615- 620.

17. Mishiro Y, Oki T, Yamada H, Wakatsuki T, Ito $\mathrm{S}$. Evaluation of left ventricular contraction abnormalities in patients with dilated cardiomyopathy with the use of pulsed tissue Doppler imaging. J Am Soc Echocardiogr 1999; 12:913-920.

18. Weidemann F, Jamal F, Sutherland GR, Claus P, Kowalski $M$, Hatle L, De Scheerder I, Bijnens B, Rademakers FE. 
Myocardial function defined by strain rate and strain during alterations in inotropic states and heart rate. Am J Physiol Heart Circ Physiol 2002; 283:H792-H799.

19. Yu CM, Lin H, Yang H, Kong SL, Zhang Q, Lee SW. Progression of systolic abnormalities in patients with "isolated" diastolic heart failure and diastolic dysfunction. Circulation 2002;105:1195-1201.

20. Bountioukos M, Schinkel AF, Bax JJ, Lampropoulos S, Poldermans D. The impact of hypertension on systolic and diastolic left ventricular function. A tissue Doppler echocardiographic study. Am Heart J 2006; 151:1323.

21. Paulus WJ, Heyndrickx GR, Nellens P, Andries $E$. Impaired relaxation of the hypertrophied left ventricle in aortic stenosis: effects of aortic valvuloplasty and of postextrasystolic potentiation. Eur Heart J 1988;9(suppl):25-30.

22. Bruch C, Stypmann J, Grude $M$, Gradaus $\mathrm{R}$, Breithardt G, Wichter T. Tissue Doppler imaging in patients with moderate to severe aortic valve stenosis: clinical usefulness and diagnostic accuracy. Am Heart $J$ 2004; 148:696-702.

23. Chambers J, Takeda S, Rimington H, Lambert-Hammill $M$, Shetty $C$, Wierzbicki A. Determinants of left ventricular mass in aortic stenosis. J Heart Valve Dis 2004; 13:873-880. 